\title{
Life after ICU: five minutes with . . . Ron Daniels
}

The consultant in intensive care and anaesthesia and UK Sepsis Trust founder talks about life after intensive care for covid-19 patients

\section{Jacqui Thornton}

London, UK

"Like many intensivists, one of the most rewarding parts of the job for me has changed over the years from acute care delivery to managing patients' and relatives' anxieties, and too often the dying process as well. With covid-19, this role has largely gone. "Relatives aren't around in the intensive care unit to mentally record the patient's journey in order to fill in the gaps for them when they recover-and aren't always there during their passing. "For patients who do survive, discharge home is traumatic, with little, disordered, or no memory of what's happened to them and difficulties returning to function.

"Normally, in the aftermath, a relative can advocate for the loved one who feels weakened, with a low mood, but can't remember what's happened. They can explain to the GP, 'I saw him in intensive care. Doctors said he was going to die.'

Covid-19 survivors don't have that.

"Patients who've survived critical illness with covid-19 are likely to need many months of rehabilitation. Early indications suggest that the neurocognitive and neuropsychiatric needs of this patient group will be huge.

"The recovery profile from covid-19 bears stark similarity to that of sepsis, and bereavement is similarly sudden and indiscriminate. Sepsis is my specialist area; my team in Birmingham developed the Sepsis 6, a treatment bundle intended to empower juniors to act rapidly, in 2004-5. Now, it's in use in almost all hospitals in the UK and in 34 other countries around the world.

"I also founded the UK Sepsis Trust-a registered charity that's been in operation for a decade-which has a specialist support service for patients and relatives as one of its four pillars of activity.

"The trust has the fluidity to be able to respond very rapidly to new demand, and has just launched Covid-19 Recovery Response, ${ }^{1}$ beginning with a new downloadable booklet. ${ }^{2}$

"It's intended to help people understand what's happened to them and why, and to share their likely recovery profile with their family, friends, employers, and those caring for them in the community.

"When someone's discharged home from hospital it's easy to expect that they're back to normal. At this extraordinary time, we'll all need to realise that for survivors of critical illness this is not the case.

"Only a couple of weeks after launch our booklet has already been downloaded several thousand times and the response has been fantastic. We're now looking to bring specialist skills into our support team to supplement their intensive care and mental health nursing experience, including skills in physiotherapy, nutrition, and neurocognitive and neuropsychiatric assessment and rehabilitation."

UK Sepsis Trust. Covid-19 recovery response. 2020. https://sepsistrust.org/covid-19recovery-response.

2 UK Sepsis Trust. What you should know after leaving a critical care unit. 2020. https:// sepsistrust.org/wp-content/uploads/2020/05/Critical-Care-Booklet-220420.pdf.

Published by the BMJ Publishing Group Limited. For permission to use (where not already granted under a licence) please go to http://group.bmj.com/group/rights-licensing/ permissions 